\title{
Bilateral Chylothorax Following Total Thyroidectomy with Neck Dissection for Papillary Thyroid Cancer Case report
}

"Musallam Kashoob, ${ }^{1}$ Saleh Bawain, ${ }^{2}$ Yahya Al Badaai ${ }^{3}$

ABSTRACT: Bilateral chylothorax is a rare condition that occurs after a thyroidectomy and neck dissection, which can lead to severe morbidity and, potentially, death, if not managed properly. We report a rare complication of neck surgery and subsequent bilateral pleural effusion in a 35-year-old female patient who presented at Sultan Qaboos University Hospital in 2018 with shortness of breath and respiratory distress. The bilateral pleural effusion and related symptoms occurred one week after a total thyroidectomy with central and left lateral neck dissection. The patient was managed conservatively and subsequently recovered.

Keywords: Chylothorax; Papillary Thyroid Cancer; Thyroidectomy; Neck Dissection; Case Report; Oman.



Hylothorax CAN BE ClASSIFIED BASED ON its aetiology, such as traumatic and nontraumatic/idiopathic forms. The most common traumatic cause of chylothorax is chest surgery. ${ }^{1}$ A rarer yet serious complication is an iatrogenic chyle leak (CL) from a thoracic duct injury during head and neck surgery; this occurs in 0.5-1.4\% of thyroidectomies and 2-8\% of neck dissections. ${ }^{2-9}$ Bilateral chylothorax is an extremely rare complication that occurs after neck dissection and is potentially life-threatening. In a systematic review by Merki et al., the reported incidence of chylothorax after total thyroidectomy and neck dissection was found to be $1.85 \%{ }^{10}$ We report a case of bilateral chylothorax following total thyroidectomy with central and left lateral neck dissection which was managed conservatively.

\section{Case Report}

A 35-year-old female patient presented to the emergency department at Sultan Qaboos University Hospital in 2018 with shortness of breath and respiratory distress. Previously, the patient, who had no known comorbidities, had been evaluated for a left thyroid nodule during a routine neck ultrasound, which was later proven to be consistent with papillary thyroid cancer by fine needle aspiration cytology. The preoperative ultrasound mapping of her neck and the computed tomography scan of her contrastenhanced head and neck did not reveal any suspicious lymphadenopathy [Figure 1]. Subsequently, she under- went a total thyroidectomy. During the surgery, her thyroid tissue was found adhered to the tracheal wall, with multiple central compartment lymph nodes positive for malignant cells on the frozen section. Hence, the surgery was accompanied with bilateral central compartments level VI-VII and left lateral level II-V neck dissection.

$\mathrm{CL}$ was encountered during neck dissection and was repaired using surgical clips, prolene 5-0 suture (Ethicon Inc., Somerville, New Jersey, USA) and tissue glue. No further leakage was noted, even with positive intrathoracic pressure ventilation pos-repair. The wound was closed after the insertion of two large negative pressure neck drains. The patient was doing well during the immediate post-operative period. The neck drains were removed after ensuring that there was minimal output of less than $10 \mathrm{ml}$ and that the patient was on a fully normal diet. She was discharged two days after surgery.

However, on the seventh post-operative day, she presented to the emergency department with shortness of breath and chest tightness. Her primary examination showed oxygen saturation of $93 \%$, mild tachypnoea and tachycardia (respiratory rate: 32 breaths/min, heart rate: 112 beats/min). Physical examinations revealed a flat neck with a healing incision site and decreased breath sounds bilaterally from the lung bases to the mid-lung fields. Imaging demonstrated bilateral moderate pleural effusions with bilateral compressive atelectasis of adjacent lung parenchyma [Figure 2]. 

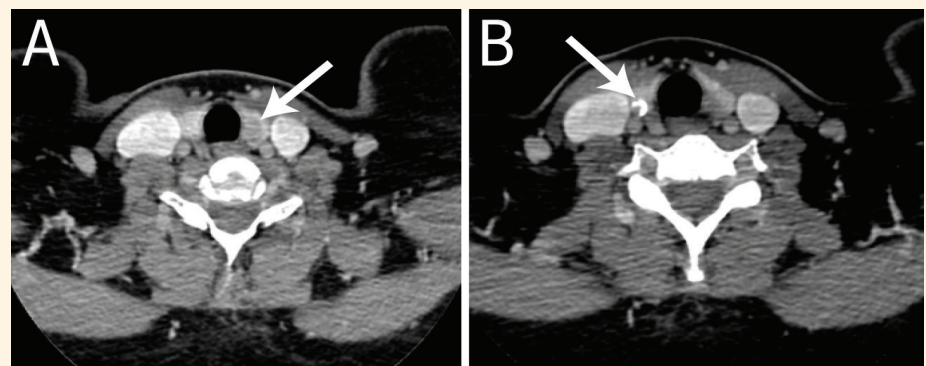

Figure 1: Contrast-enhancing axial cut computed tomography images of the head and neck of the patient showing (A) a $10 \mathrm{~mm}$ hypoattenuating nodule on the left thyroid lobe (arrow) and (B) a $7 \mathrm{~mm}$ nodule with a rim of calcification on the right thyroid lobe (arrow).

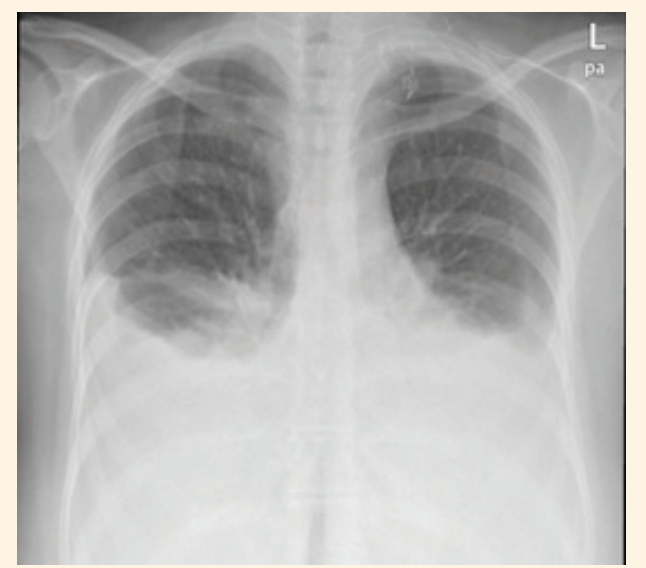

Figure 2: Posterior-anterior chest radiograph of the patient showing bilateral moderate chylothorax with associated atelectasis and post-thyroidectomy surgical clips at the base of the neck.

Intrathoracic pleural catheters were placed bilaterally, which drained approximately 2.5 litres of chylous fluid from both sides. Pleural fluid analysis showed a triglyceride level of $5.7 \mathrm{mmol} / \mathrm{L}$ (normal range: $0.0-2.3 \mathrm{mmol} / \mathrm{L}$ ), which confirmed chylous fluid. The patient was started on a fat-free diet and somatostatin analogue injection (octreotide $100 \mathrm{mcg}$ every 8 hours, subcutaneously) along with chest physiotherapy, intravenous antibiotics and daily monitoring of drain output and electrolytes. Chest drains were draining $<50 \mathrm{~mL}$ on the consecutive follow-up days and a chest X-ray confirmed a marked improvement of the effusions bilaterally after use of the mentioned conservative measures alone. The chest drains were kept for seven days and the patient did not show any radiological signs of re-accumulation or persistent leakage [Figure 3].

The histopathological diagnosis showed a tall cell variant of papillary thyroid carcinoma (tumour size: $2.5 \mathrm{~cm}$ ) with 11 metastatic lymph nodes out of a total of 88 lymph nodes (largest measuring $1.4 \mathrm{~cm}$ ). The patient recovered well and received a treatment dose of radio-iodine therapy.

The patient provided consent for the publication of this case report.

\section{Discussion}

The pathophysiology of bilateral chylothorax is still not fully understood, but there are two proposed mechanisms of injury. ${ }^{10}$ The first mechanism includes direct injury or incomplete ligation of the duct during surgery, due to variable duct anatomies described earlier. $^{8,11}$ This first mechanism results in CL into the mediastinum. The second possible mechanism of injury is due to increased retrograde hydrostatic pressure in the thoracic duct, resulting in increased intraluminal pressure. This, combined with negative intrathoracic pressure, causes a secondary rupture within the chest. Based on the current patient's intraoperative and post-operative clinical profile and radiology, it is presumed that the second mechanism is responsible for the bilateral chylothorax in this case.
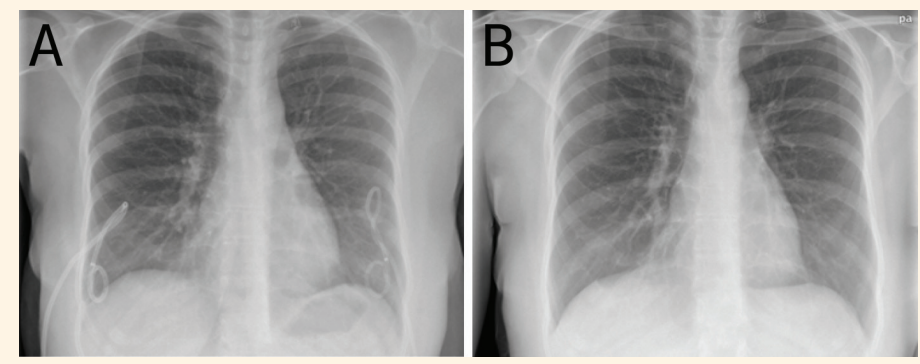

Figure 3: Postreior-anterior chest X-rays at seven days follow-up showing (A) near-total resolution of the chylothorax post-placement of the bilateral intrathoracic pleural catheters and (B) clear lungs and costophrenic angles. 
Early diagnosis and appropriate management are essential in order to avoid chylothorax-related morbidity. This can be in the form of either cardiopulmonary compromise or metabolic derangement including loss of proteins, electrolytes, fluid, fat, fat-soluble vitamins and $\mathrm{T}$ cell lymphocytes. ${ }^{12}$

Although a comprehensive clinical assessment with imaging may point to the diagnosis of chylothorax, chemical analysis of the pleural fluid is essential for diagnosis. Chylothorax is present in $99 \%$ of patients with an aspirate triglyceride content of $>110 \mathrm{mg} / \mathrm{dL}$ $(1.24 \mathrm{mmol} / \mathrm{L})$ and a cholesterol content of $>200 \mathrm{mg} / \mathrm{dL}$ $(5.1 \mathrm{mmol} / \mathrm{L})$. Moreover, the presence of chylomicrons in the pleural fluid is considered diagnostic. ${ }^{13-15}$ The pleural aspirate triglyceride content in the patient was $5.7 \mathrm{mmol} / \mathrm{L}$.

Operating surgeons should have a clear concept of the tortuous anatomy of the thoracic duct to avoid complications. At the level of the upper lumbar spine, the thoracic duct starts as cisterna chyli. It has different anatomical relations when it passes within the abdomen, thoracic cavity, root of the neck and before it terminates. Initially, it ascends upward along the abdominal aorta and azygos vein, then through the aortic orifice overlying the vertebral column to enter the thoracic cavity. Then, it turns to the left side and continues to pass upwards in the posterior mediastinum to enter the root of the neck. At this level, it passes lateral to the oesophagus, medial to the omohyoid muscle, posterior to the left carotid sheath and anterior to the vertebrae. Then, the thoracic duct courses superiorly and laterally before it descends inferiorly to arch over the anterior scalene muscle, phrenic nerve and subclavian artery, before ending within $1 \mathrm{~cm}$ from the confluence of the internal jugular vein and subclavian vein. ${ }^{16-18}$ However, there are anatomical variations of the terminal course of the thoracic duct: in $46 \%$ of the cases, it enters the internal jugular vein and in $32 \%$ of cases, it enters the junction of the internal jugular and subclavian veins. Less commonly, it may enter the subclavian vein in $18 \%$ of the cases. Although two or three endpoints of thoracic duct terminations have been described, usually it ends as a single duct in about $76 \%$ of the cases. ${ }^{8,11}$

Management of chylothorax should be tailored to each case as it varies between conservative approaches, interventional radiological approaches and surgical options. Conservative measures include the drainage of the chylothorax in addition to diet modifications in the form of medium-chain triglycerides, a fatfree diet or total parenteral nutrition to reduce chyle production. In addition, certain medications are used such as somatostatin or its analogue or octreotide to reduce chyle production. ${ }^{19,20}$ However, there is no consensus as to how long these medications should be used. If the quantity of drained chyle is $<500 \mathrm{~mL} /$ day, spontaneous recovery with conservative measures is more favourable. ${ }^{19}$ In the current case, conservative treatment was effective in reducing the leak to less than $50 \mathrm{~mL} /$ day. Depending on the available expertise of each centre, percutaneous lymphangiographyguided cannulation with embolisation of the leakage is another minimally invasive option. ${ }^{21}$

Surgical intervention, including thoracic duct ligation via video-assisted thoracoscopic surgery or open surgery, should be considered if conservative measures fail, drain flow is more than $1 \mathrm{~L} /$ day or severe metabolic complications are present. However, there are currently no prospective studies available to compare the efficacy of different approaches.

\section{Conclusion}

Bilateral chylothorax is a rare and potentially lifethreatening complication, which should be considered in all patients with post-operative dyspnoea occurring after central or left lateral neck dissection. Early diagnosis and intervention are crucial for best outcomes. Management is tailored according to the clinical scenario, level of expertise available and patient response to the initial treatment.

\section{AUTHORS' CONTRIBUTION}

MK drafted the manuscript and performed text data mining. All Authors were involved in management of this case and approved the final version of the manuscript.

\section{References}

1. Skandalakis JE, Skandalakis LJ, Skandalakis PN. Anatomy of the lymphatics. Surg Oncol Clin N Am 2007; 16:1-16. https://doi. org/10.1016/j.soc.2006.10.006.

2. Lee YS, Kim BW, Chang HS, Park CS. Factors predisposing to chyle leakage following thyroid cancer surgery without lateral neck dissection. Head Neck 2013; 35:1149-52. https://doi. org/10.1002/hed.23104.

3. Lorenz K, Abuazab M, Sekulla C, Nguyen-Thanh P, Brauckhoff M, Dralle H. Management of lymph fistulas in thyroid surgery. Langenbecks Arch Surg 2010; 395:911-17. https://doi.org/10.1 007/s00423-010-0686-2.

4. Roh JL, Yoon YH, Park CI. Chyle leakage in patients undergoing thyroidectomy plus central neck dissection for differentiated papillary thyroid carcinoma. Ann Surg Oncol 2008; 15:2576-80. https://doi.org/10.1245/s10434-008-0017-9.

5. Rammal A, Zawawi F, Varshney R, Hier MP, Payne RJ, Mlynarek AM Chyle leak: A rare complication post-hemithyroidectomy. Case report and review of literature. Otolaryngol Pol 2014; 68:204-7. https://doi.org/10.1016/j.otpol.2014.03.003. 
6. Dhiwakar M, Nambi GI, Ramanikanth TV. Drain removal and aspiration to treat low output chylous fistula. Eur Arch Otorhinolaryngol 2014; 271:561-5. https://doi.org/10.1007/s00405-0132534-9.

7. Nussenbaum B, Liu JH, Sinard RJ. Systematic management of chyle fistula: The Southwestern experience and review of the literature. Otolaryngol Head Neck Surg 2000; 122:31-8. https://doi.org/10.1016/S0194-5998(00)70140-9.

8. Langford RJ, Daudia AT, Malins TJ. A morphological study of the thoracic duct at the jugulo-subclavian junction. JCraniomaxillofac Surg 1999; 27:100-4. https://doi.org/10.1016/s1010-518 2(99)80021-3.

9. Crumley RL, Smith JD. Postoperative chylous fistula prevention and management. Laryngoscope 1976; 86:804-13. https://doi. org/10.1288/00005537-197606000-00008.

10. Merki V, Pichler J, Giger R, Mantokoudis G. Chylothorax in thyroid surgery: A very rare case and systematic review of the literature. J Otolaryngol Head Neck Surg 2016; 45:52. https:// doi.org/10.1186/s40463-016-0166-y.

11. Phang KL, Bowman M, Phillips A, Windsor J. Review of thoracic duct anatomical variations and clinical implications. Clin Anat 2014; 27:637-44. https://doi.org/10.1002/ca.22337.

12. Valentine VG, Raffin TA. The management of chylothorax. Chest 1992; 102:586-91. https://doi.org/10.1378/chest.102.2.586.

13. Staats BA, Ellefson RD, Budahn LL, Dines DE, Prakash UB, Offord K. The lipoprotein profile of chylous and nonchylous pleural effusions. Mayo Clin Proc 1980; 55:700-4.
14. Skouras V, Kalomenidis I. Chylothorax: Diagnostic approach. Curr Opin Pulm Med 2010; 16:387-93. https://doi.org/10.1097/ MCP.0b013e328338dde2.

15. McGrath EE, Blades Z, Anderson PB. Chylothorax: Aetiology, diagnosis and therapeutic options. Respir Med 2010; 105:1-8. https://doi.org/10.1016/j.rmed.2009.08.010.

16. Kwon SS, Falk A, Mitty HA. Thoracic duct injury associated with left internal jugular vein catheterization: Anatomic considerations. J Vasc Interv Radiol 2002; 13:337-9. https://doi.org/10.1 016/s1051-0443(07)61730-8.

17. Van Pernis PA. Variations of the thoracic duct. Surgery 1949; 26:806-9.

18. Ammar K, Tubbs RS, Smyth MD, Wellons JC 3rd, Blount JP, Salter G, et al. Anatomic landmarks for the cervical portion of the thoracic duct. Neurosurgery 2003; 53:1385-8. https://doi. org/10.1227/01.NEU.0000093826.31666.A5.

19. Bender B, Murthy V, Chamberlain RS. The changing management of chylothorax in the modern era. Eur J Cardiothorac Surg 2016; 49:18-24. https://doi.org/10.1093/ejcts/ezv041.

20. Huggins JT. Chylothorax and cholesterol pleural effusion. Semin Respir Crit Care Med 2010; 31:743-50. https://doi.org/10.105 5/s-0030-1269834

21. van Goor AT, Kröger R, Klomp HM, de Jong MA, van den Brekel MW, Balm AJ. Introduction of lymphangiography and percutaneous embolization of the thoracic duct in a stepwise approach to the management of chylous fistulas. Head Neck 2007; 29:1017-23. https://doi.org/10.1002/hed.20624. 